\title{
US agencies urged to tighten up peer review
}

Washington. New guidelines have been published in Washington in the hope of improving the procedures used by the various US government agencies that make grants to scientists on the basis of peer review. In particular, the guidelines are aimed at safeguarding the confidentiality of material submitted for review, and ensuring that reviewers have no conflicts of interest.

The guidelines have been produced by a small federal agency, the Administrative Conference of the United States, which advises government departments and federal agencies on good administrative practice. They outline steps which, the conference suggests, grant-making agencies should take to help achieve both objectives.

But the proposed guidelines are not binding. And critics say the conference has drawn back from making more contentious suggestions - for example that agencies should be required to inform applicants of their legal right to complete information about why grant applications have been rejected.

The guidelines have been drawn up largely on the basis of a report by Tom McGarity, professor of law at the University of Texas. According to McGarity, peer reviewers who steal ideas have become a serious problem, and the problem is likely to get worse with the increasing financial pressure in scientific fields such as genetics. "It is one of those things on the soft underbelly of science which no-one likes to talk about," he says.

The Administrative Conference says that federal agencies should warn all peer reviewers in writing of their obligation to respect the privacy of authors, and of the penalties of transgression. As with many of the other suggested guidelines, this would

\section{McBride struck off}

Sydney. William McBride, who first alerted the world to the dangers of thalidomide, was struck off his state medical register in Australia last week because he falsified scientific data.

The Medical Tribunal of New South Wales, sitting in Sydney, voted 3 to 1 on the decision, which effectively ended the 67 year-old researcher's career, but expressed its "profound regret" over the move.

The tribunal found that McBride's character was "flawed", following an earlier finding that the researcher had altered and falsified scientific data.

After a marathon hearing in February, the tribunal found that McBride had changed data on the effect of a drug, related to the morning sickness drug Debendox, on a group of rabbits, to support his views that the related drug caused birth defects.

Mark Lawson lead smaller grant-giving agencies to fall in line with existing practice at the two largest agencies, the National Science Foundation (NSF) and the National Institutes of Health (NIH).

"These two agencies have thought long and hard about it, and, compared with the smaller agencies, they have a sophisticated approach," says Charles Pou, a lawyer at the Administrative Conference.

But not everyone agrees that the big two already have it right. Jon Kalb, a geologist at the University of Texas, complains that the NSF - in contrast with NIH - fails to inform grant applicants of their full rights on the application form. Kalb won a victory over the NSF in 1987 over the reasons for which he had been denied funding for earlier research work after a protracted legal battle. His success led, in part, to the McGarity report, and to the proposed new regulations.

Lawrence Rudolph, a lawyer at the NSF, says that such information would be a waste of space on the form, since grant applicants now receive copies of the peer reviews of their applications as a matter of course. He concedes, however, that applicants do not at present automatically receive copies of the internal NSF document spelling out the full reasons for their rejection or acceptance. Kalb says that the NSF has "gone to great lengths" not to let scientists know what information they are entitled to.

On the question of releasing information and informing applicants of their full rights, McGarity says that NIH is "the model agency, out there in front". Since Kalb's court case, he adds, NSF has "come around" in matters of substance. The main problem now lies with the smaller grant-giving agencies, including the research divisions of most government departments.

McGarity also supports the idea of putting a lay person on each peer review panel. Congress ordered the National Endowment for the Arts to do this when it found out that much art being supported by grants was subversive material inimical to the American way of life.

But the proposal has few backers in the scientific community. "Scientists were just violently against the idea," says McGarity. In its proposed guidelines, the Administrative Conference merely asks agencies "to consider panellists who are not peers but who bring perspectives relevant to the [funding] decision".

Colin Macilwain

\section{Satellite research 'needs more money'}

Washington. The US satellite communications industry faces a rout by its Japanese and European rivals because of lack of government coordination and inadequate support for research and development, claims a panel of experts.

A report compiled by leading scientists and engineers in the field and funded by the National Aeronautics and Space Administration (NASA) says the United States retains a "technology lead" in only five out of 19 key advanced technologies. In contrast, Japan leads in eight, including batteries, solar arrays and overall system design.

Europe is not considered to have an outright lead in any of the technological areas considered. But the report still applauds what it sees as the successful industrial policy led by the European Space Agency (ESA) in satellite communications.

"NASA just isn't supporting the industry to the extent that ESA and NASDA [the Japanese space agency] are", says Burton Edelson, a former senior administrator at NASA who acted as a co-chairman of the 12-strong panel. Its report was based on visits by the panel to Western Europe, Japan and Russia, and was released last week by the International Technology Research Institute at Loyola College, Maryland.

According to Edelson, almost all of NASA's heavy spending in the past has been directed to distinct programmes. As a result, he says, no money has been spent on important generic technologies needed to ensure the future strength of the United States in what is becoming a fiercely competitive field.

The report does not explain why corporations that have previously benefited from NASA's largesse now find they are unable to crush upstart competition from Europe and Japan. But Edelson denies that this reflects badly on the way in which NASA spends its \$15-billion annual budget. "It's more a reflection of the work NASA hasn't done", he says.

"We are arguing that NASA should spend a higher percentage of its money on satellite communications, not that it should spend more money overall," says Edelson. He points to the $\$ 200$ million that NASA spends each year on microgravity research as an example of money that could be better spent in an area such as satellite communications, where commercial spin-off is assured.

The publication of the panel's report coincides with concern being expressed by the satellite communications industry that NASA's Advanced Communications Technology Satellite programme, whose budget peaked at $\$ 100$ million, is now nearing its end, but that no replacement is in prospect.

Colin Macilwain 